\title{
Chinese College Students' Views on Native English and Non-native English in EFL Classrooms
}

\author{
Yang Qian \\ School of Foreign Languages, China, Three Gorges University, 8 Daxue Road, \\ Yichang City, 443002, Hubei Province, PR, China \\ E-mail: skipalong_hi@163.com \\ Liu Jingxia (Corresponding author) \\ School of Foreign Languages, China, Three Gorges University, 8 Daxue Road, \\ Yichang City, 443002, Hubei Province, PR, China
}

Doi:10.7575/aiac.alls.v.7n.4p.84

URL: http://dx.doi.org/10.7575/aiac.alls.v.7n.4p.84
Received: 12/03/2016

Accepted: 10/05/2016

The research is financed by Three Gorges University, China. No. 2015 CX157 and Hubei Province Ministry of Education, China. No. 2013 B071.

\begin{abstract}
With the development of globalization, English is clearly spoken by many more non-native than native speakers, which raises the discussion of English varieties and the debate regarding the conformity to Standard English. Although a large number of studies have shown scholars' attitudes towards native English and non-native English, little research is conducted from the point of college students until recently. This paper focuses on Chinese college students' perceptions of native English and non-native English in order to offer insights into the mainstream English language teaching in terms of its exclusive reference to English as a native language in China. This paper draws on the data contributed by 50 Chinese university students through questionnaires. The questionnaire responses displayed a superficial preference for native English and a potential inclination for non-native English in EFL classrooms. The article argues that factors behind the attitude point to the need of changing mainstream English teaching.
\end{abstract}

Keywords: Native English, Non-native English, Chinese college students' attitudes, mainstream English teaching

\section{Introduction}

With the development of globalization, English has within a relatively short time become a language used by far more bilingual and multilingual speakers than monolinguals. The long and widespread use of English has led to non-native varieties such as Japanese English, Indian English or China English. Kachru's (1992 in Murray 2003) principle of three concentric circles defines that Native English-Spoken countries belong to inner circle (for countries where English is spoken as the main first language, e.g. in the U.S. or Britain), second English language pertains to outer circle including countries where English is used as an additional institutionalized language, though not a mother tongue, e.g. in India or Nigeria and expanding circle including countries where English is widely studied as a foreign language, e.g. in China or Korea. British English and American English are regarded as the mainstream languages in China. Therefore, in this paper, native English refers to British English and American English. Non-native English includes Englishes which are used differently from American English and British English.

When referred to native English and non-native English in English language teaching, Cook (1998 in Timmis 2002) has ever asked a very simple and challenging question: why should the attested language use of a native speaker community be a model for learners of English as an international language? In Murray's (2003) study, native English is considered as currently prestigious. Not only do teaching materials around the world take native English as their model, but they also largely represent English as the medium of communication between two native speakers or between native speakers and non-native speakers. According to Seidlhofer (2011 in Wang 2013), non-native English manifests how non-native speakers exploit their communicative resources to suit their pragmatic purposes. However, Timmis (2002:249) answers as follows: There is no reason why it should, but it may be that some students want it to be, even when we least expects it. These studies show different attitudes towards native English and non-native English in English language teaching.

As far as ELF (English as a lingua franca) research is concerned, little has been published with the focus on Chinese college students specifically. Among the very few publications which shed lights on English language teaching, Timmis (2002) draws the conclusion that many students have the desire to conform to native speaker norms. In Ranta's (2010 in Wang 2013) study, Finnish students are likely to aspire for native-like English at the macro-level, and simultaneously they tend to accept their own Englishes at the micro-level. Erling's (2007 in Wang 2013) study on university students 
from Germany draws a similar conclusion. In Hu's (2004) study, most Chinese students prefer native English. She thus calls for an equal place for China English, as a non-native English, to stand in the rank of global English. Wang's (2013) study offers some implications for English education in China, demonstrating that her research participants' attitudes towards non-native English are slightly positive but surface their struggle between the formulaic conformity to native English and the functions of non-conformity. With the focus on Chinese college students' views on native English and non-native English, this paper explores factors behind the attitudes and considers possible implications of the findings for English language teaching in China.

In the rest of this paper, we will first describe the division between native English and non-native English in China, which proceeds to the discussion of English teaching in Chinese universities. We will also report the process of data collection before we present and discuss the findings, which leads to a call for pedagogical change.

\section{Native English and Non-native English in China}

\subsection{Native English in China}

In China, English is taught as a foreign language (EFL). The target language is almost exclusively an idealized form of some English native language (ENL) varieties, which is usually British or American English. The reason why native English is so popular in China can be divided into follows. In Wang's (2013:272) study, from Chinese English speakers' perspective, native English has three features that native English is the essence of English with a fixed standard which can fulfill their wants for social advantages. Although there are some participants who choose to leave native English norms aside in Wang's study, these three features can still explain the popularity of native English in China. Besides, native English has its prevalence in popular culture, which can also be attested in Murray's (2013:115) study, native English provides accesses to the most popular sports and entertainments, especially on ball games and films. When mentioned NBA, almost every young boy can talk about it for several minutes. It is also definitely possible that there are some English songs in the music list of Chinese people. More and more English movies are introduced into China; they are as popular as Chinese film or even more popular. With the development of globalization, Chinese people are eager to know more about American culture and British culture. What's more, native English is the current dominance, especially in business and scientific communications. Murray (2003) discusses that English opens up communications with the rest of the world. Chinese business focuses on domestic market before the widespread use of English. The popularity of English builds a bridge between domestic markets and foreign markets. It provides an easy access for people to communicate with people from other countries. In scientific study, native English is becoming more prevalent not only as the lingua franca of research but also of instructions (Murray, 2003). Learners and scientists worldwide use native English to make research programs and communicate with each other because of its accuracy and precision. English is also currently prestigious. As Truchot ( 2002:21 in Murray 2003) remarks, what gives English its status... is not so much its utilitarian function as the prestige attached to it and the social role attributed to it. The prestige of English makes it a fundamental skill for employees to use English proficiently. People equipped with the skill are more popular than those who do not have. From the reasons discussed above, it can de inferred that many Chinese English speakers think that native English has many inherent advantages which makes it important in different areas. Thus, not only English learners but also anyone or any organization that can benefit from the popularity of native English pay much attention to it. However, it does not mean that all Chinese English speakers recognize native English as the only reference. From Wang's (2013) study, it is easy to find out that there are many other people who would like to use English in their own way. Under the circumstance of globalization, native English can be seen as a main reference instead of the only one in China.

\subsection{Non-native English Speakers and Non-native English in China}

It has been a hard time for linguists reaching consensus on the exact identity of non-native speakers. Fazeb (2007 in Moussu 2008) confirms that linguistic identities are complex, dynamic, relational, dialogic and highly contextdependent. In the world, the first attempt to put '(non-)nativism' onto the center stage of linguistic inquiry by challenging current undisputed assumptions on the matter was Paikeeday's The native speaker is dead. (Paikeday, 1985: 12 in Lucie Moussu 2008). He suggests using the term 'proficient user' of a language to refer to all speakers who can successfully use it. Moussu (2008:57) thinks that Parkeday seems to confuse the distinction between native English and non-native English. 'Proficient user' can be denoted as anyone who can speak English well because of training and practice. However, how to evaluate one's capacity as to whether he or she is proficiently using English becomes a question. That is, to what degree can a non-native speaker be viewed as proficient user? It is a matter of criteria. Different linguists attach different meaning to it. Davies (1991 in Moussu 2008:56) concludes that second language learners can become native speakers of the target language and master the intuition, grammar, spontaneity, creativity, pragmatic control, and interpreting quality of 'born' Native English. It is obvious that he treats the fixed coded and principles of native English as the standard. Native English is also believed by many people and has been the mainstream for many years. Following a different approach, Inbar Lourie's (2005 in Moussu 2008) data shows that many self-ascribed non-native speakers can actually pass for native speakers in certain situations. Similarly, some selfascribed native speakers in Moussu's (2006) study were taken for non-native speakers by their students. However, Moussu (2008) thinks that it is necessary to recognize the importance of a speaker's acceptance by a community as one of its numbers, as it is what will ultimately be determining the social recognition of native English and Non-native English. This social recognition is often based on judgment of the speakers' accent (Moussu, 2008:57). From his perspective, if the speaker's accent is different from the listener's, and this listener cannot recognize it as any other 'established accent', the speaker will be placed within the non-native speaker category. Park (2007 in Moussu 2008) 
analyzes how non-native speakers' identities are so-constructed through interaction. The discussion of the identity of non-native speakers also touches upon the issue of linguistic rights and identity protection. Wang's (2013:259) study demonstrates that the World Englishes research has effectively defended outer circle users' right of using English in their way. Widdowson's (1994 in Wang 2013) discussion of the issue about the ownership of English challenges the exclusive control of English by native English speakers and provides support to non-native English speakers' right to English. The two exceptions in Bull's (2012) study that have a different language policy and different linguistic practices against mainstream also prove that by using English in their own way, they can protect their cultural identity. With an increasing awareness that English belongs to all those who use it, non-native speaker's needs and wants in their use of English are also emphasized.

Linguistic theory has traditionally considered native speakers as the only reliable source of linguistic data (Chomsky 1965 in Moussu 2008). It is therefore not surprising to find only a limited number of works in China focus on nonnative speakers. In China, Wang (2013:261) thinks that 'the understanding of non-conformity to ENL norms in an ELF perspective challenges the traditional view of language as a fixed system of codes and aligns with the view of language as a social practice in which ELF users are languagers engaged with different resources and strategies in order to achieve their purposes'. She thinks that mutual intelligibility between interlocutors is achieved through accommodation and meaning negotiation rather than conformity to prescribed codes. That is, non-native English speakers do not need to conform to the norms of native English. Language cannot be viewed as the end-product generated by its user but the means through which users can achieve their purpose of communication, such as information exchange and business transaction. There are many linguists who currently advocate non-native models for the teaching of English. Hu (2004) calls for an equal place for China English, as a non-native English, to stand in the rank of world Englishes. Bull (2012) gives explanations to the two exceptions (Smi allaskuvla and Kautokeino) that have a different language policy and different linguistic practices against the mainstream. Wang (2013) argues that the mainstream English teaching needs changes on the basis of her study of Chinese English speakers. There are several reasons for this trend. Firstly, given the language needs of Chinese learner of English, it seems pointless for them to strive to attain a goal that is beyond their reach. Very few of them will ever need to attain a native-like level, although they may aspire to do so. Teachers testify to the fact that many non-English majors, and even some English majors, seem to want no more than a reading and working level of English at a practical spoken level (Ma, 2012:106). Secondly, they see it as a vehicle for transmitting Chinese culture through the translation or transliteration of different terms (He and Li 2009 in Ma 2012). As is know to all, language and culture are closely related with each other. With the development of globalization, the international exchange of culture becomes common and inevitable. By using English in different way, Chinese can display their culture and spread it all over the world. For example, 'Long time no see' is universally acknowledged now. Kongfu, Yingyang and many Chinese words are added into English vocabulary. Jackie Chen's film is a hit in Hollywood. Patterns with Chinese unique elements, such as blue and white porcelain are used in the French fashion. It is a good way to make Chinese culture known by the rest of the world.

\section{English Language Teaching in Chinese Universities}

The increasing use of English as a lingua franca in research and as a medium of instruction in higher education institutions seems to have made strong impact in China. For some years now, China has been cited as the major English learning society, where the number of English learners has been estimated at more than 200 million people (Bolton and Graddol, 2012). Chinese English speakers are in the expanding circle of Kachur's model. They normally use English to communicate with people who do not speak Chinese. English is regarded as one of the most important subjects in China. The educational institutions attach as much importance as Chinese and math to English. All students at university in China, irrespective of their major area of study, are required to learn English, not only to enter university but also to graduate. Those majoring in subjects other than English are required to pass the College English Test (CET) before graduation. Chinese students start to learn English when they are in third grade in the primary school. During their process of learning, native English is seen as the main reference. In their test, grammar related questions can be easily found in multiple choices and cloze. The vocabulary in their text book is either American English or British English pronounced. The focus of English teaching in China has so far remained very much on 'cumulative' proficiency (becoming better at speaking and writing English as native speakers do) and on the goal of successful communication with native speakers and for some levels, approximating native-like command of the language (Seidlhofer 2002b:13 in Wang 2013). That is, British English or American English has always been the ideal target language for Chinese college students. Native speaker culture regularly provides the content or context for English lessons. For Chinese college students, native speakers are used to being authorities on what is and what is not English and it is almost impossible to relinquish the privileged position of native English. Native English teachers are often labeled as native speakers. From Moussu's (2008) study, thousands of language teaching jobs, specifying that only native speakers will be considered, are advertised in many counties and educational institutions and contexts, addressing a hypothetical preference by second language learners for native speakers rather than non-native speaker's teachers. In other words, native English teachers are preferred by second language learners because they are often regarded as a carrier of native English. As can be imagined, non-native English teachers are at a distinct disadvantage in areas of the English language teaching (ELT) world where a perfect command of English native language (ENL) is assumed to be necessary, and may thus enjoy less prestige and power. Non-native speakers of English who want to teach in China will find that their options are limited. The discussion of whether native English teachers or non-native English teachers are more favorable for Chinese college students to teach Chinese students English is of great importance to English language teaching in Chinese universities. There are several researches about native English teachers and non-native English teachers. 
Canagarajah(1999 in Moussu 2008:63) thinks that native English-speaking teachers will be better teachers in EFL contexts, because of their unique cultural knowledge, whereas non-native English-speaking teachers would be better teachers in ESL contexts, because of their multicultural experience. Medgyes(1994 in Moussu 2008 ) describes six positive characteristics of non-native English-speaking teachers:1) They provide a good learner model to their students; 2)They can teach language strategies very effectively; 3)They are able to provide more information about the language to the students; 4)They understand the difficulties and needs of the students; 5) They are able to anticipate and predict language difficulties; 6)In EFL setting, they can use the students' native language to their advantage. However, nonnative teachers still have challenges in language proficiency and lack of training or re-development programmes (Xie and Jian, 2006). Non-native English teachers learn English as a second language or foreign language, and they seldom use it in their daily life except in the classroom. It will also be difficult for non-native English speaking teachers to explain the background of a text and the idioms related to the culture if they are not good at understanding the culture of English speaking countries. Native and non-native teachers' differences, strengths and weakness demonstrate their different teaching contents and teaching methods, which also emphasizes different aspects of English. Students' preference for different kinds of teachers reflects their aspiration for different kinds of Englishes.

In the finding of Moussu's (2002:67) project, among ESL students at a US university, Chinese students hold the most negative attitudes towards their non-native English-speaking teachers, while non-native teachers who sound and look 'foreign' were less appreciated than those who look and sound like native speakers of English. The result of $\operatorname{Li}(2006)$ indicates that students expect their English teacher of both native and non-native camps to offer more chances to practice English language use, especially from the perspective of speaking, more chances to contact with teachers to get more opportunities to communicate and improve their English language. From her study, special expectations are given to native English-speaking teachers for their lack of Chinese language and cultural knowledge, which leads to confusion and misunderstanding between the teachers and the students, and also to the non-native English-speaking teachers for their English language proficiency, who are certainly not as competent as native teachers for the target language, especially in terms of pronunciation.

According to Noss (1971:42 in Peng 2013), there are three levels of English Foreign Language (EFL) policy and planning: educational, official, and general. Educational policy addresses questions of language use in different kinds of schools; official policy deals with what languages are to be used at official level; general language policy discusses language use in mass communication, business and contacts with foreigners. Spolsky (1999 in Peng 2013) argues that the position of the foreign language guides policy makers significantly in their approach. For most policy maker, English is principally treated as a tool or instruction media but actually it is so much more. Wang (2002 in Peng 2013) views English as a window, enabling each nation to communicate with other countries and to collect new concepts, nations and observe new movements to bring them back to analyzed for further necessary inputs. As what has been referred in Reis's (2011:147) study, who I am does affect how I teach or how I look at my self. That is, the selfconception and the identity of the intuitions influence their policies and practices. In China, English is a compulsory course which should be started to learn from Grade 3. The government has invested considerable recourses into English language teaching. In the same time, English education market has been a major industry in China. In Bull's (2012) words, higher education is a community. English as a hegemonic global language is the linguistic solution in a multilingual world with free movement of capital, goods and labor. Although native English has been prestigious in English language teaching, some changes are taking place. Beijing Municipal Education Commission makes a new scheme for the reformation of the college entrance examination, which turns the total score of the English from 150 to 100. The Ministry of Education also kicks English out of unified examination in a new scheme and changes it into several times of examinations. It is said that English will no longer be tested in the college entrance examination since 2020. Professor Wang Ling in Tsinghua University thinks that English should not be excluded from the college entrance examination, but different colleges can choose their students according to their own needs and wants. It seems that the reformation makes English less important than before. However, the development of globalization inevitably leads to the globalization of education, it is impossible to ignore the importance of English. These policies and reformations can also be treated as an opportunity to learn and use English as one likes. Less restrictions and prestige attached means more freedom. People are able to learn and use English according their ability, expectations and requirements.

English has been popularized in China for several years. With the exploration of English language teaching, more and more desires and wants need to be taken into consideration. The original idea that Native English norms should never be questioned is not suitable for the current environment. English language teaching needs to change from native English only reference to English varieties.

\section{Methodology}

This paper focuses on the findings retrieved from a questionnaire. The questionnaire is to survey Chinese college students' views on native English and non-native English in EFL classrooms. The questionnaire is sent by e-mail to 50 college senior English major students of China Three Gorges University. The questionnaire has ten multiple choice questions and one open question. All the questions are designed to be objective without any preferences and bias and to minimize inductivity to have the respondents express their views. Question 5 and 6 are selected from Murray's Swiss English Teacher and Euro-English (2003). The main contents focus on students' attitudes and preferences of native English and non-native English. The questionnaire uses a 5-point scale of responses ranging from 'completely acceptable' through 'uncertain' to 'completely unacceptable'. All the respondents participated are volunteered to take 
part in this survey. We promise that the related information of any respondents would not be revealed and all the respondents be kept anonymous in answering the questionnaire. In the end, all the related questionnaires and notes are destroyed to be sure of the interests of the respondents. The aims of the questionnaire are twofold. First, we want to find out about Chinese college students attitudes towards native English and non-native English in EFL classrooms, and second, we want to find out the reasons behind that attitude. The specific analysis method is conducted as the following three steps. First, the ten multiple-choice questions are calculated in terms of the percentage, mean number and mode of each option respectively and classified with the statistical data to make analysis. Second, the answers to the open question are analyzed to explore some reasons of students' preferences that multiple-choice questions do not refer to. Finally, the first two parts of the survey are combined together to find out students' attitudes and possible reasons for this trend. This paper aims to provide some information concerned with Chinese college students' attitudes towards native English and non-native English in EFL classrooms, hoping that the data can reflect Chinese college students' needs and expectations. By deeper analysis of students' attitudes, needs, expectations and the place of English in current conditions, this paper explores the reason why students hold different opinions towards native English and non-native English. This paper aims to make students' voice heard in the process of English teaching, but it will not enlarge their needs infinitely and unilaterally. Together with different needs for English in current environment, it tries to give some useful information for the change of English teaching.

\title{
5. Results: Chinese College Students' views on Native English and Non-native English
}

\subsection{Learners and Learning}

Chinese college students prefer native English than non-native English in terms of pronunciation. However, they do not think that non-native English has many grammatical mistakes and phonetic mistakes. Besides, during the process of learning English, they expect to know more different forms of English.

Diagram 1 is a full description of Chinese college students' preference between native English and non-native English. Almost half of the students agree that native English sounds more beautiful and authentic than non-native English. A similar conclusion is drawn in the open question. The majority favors native English with the focus on its pronunciation. However, it does not mean that they reject any other English forms except native English. From diagram 1 , it is easy to find that respondents who disagree with the statement are just $14 \%$ less than those who agree. The result of diagram 2 reinforces this point. Statement 2 is designed to find out whether students think that non-native English has many grammatical mistakes and phonetic mistakes. For the group of respondents as a whole, there is no clear majority, although it receives the highest percentage (32\%) of respondents choose the "Mildly Acceptable". Students are almost evenly divided in terms of pro and con responses, showing that there are still many students who consider the grammar and pronunciation of non-native English valid. Diagram 3 gives a new viewpoint on the issue. Learners are eager to have more say in whether they imitate native speaker or non-native speaker. A comfortable majority (52\%) agree with the statement, which demonstrates that learners want to have the initiative to choose what kind of English they should learn. It reflects that students doubt the mainstream English teaching and want to challenge the traditional teaching model.

\section{Statement 1: Native English sounds more beautiful and authentic than Non-Native English}

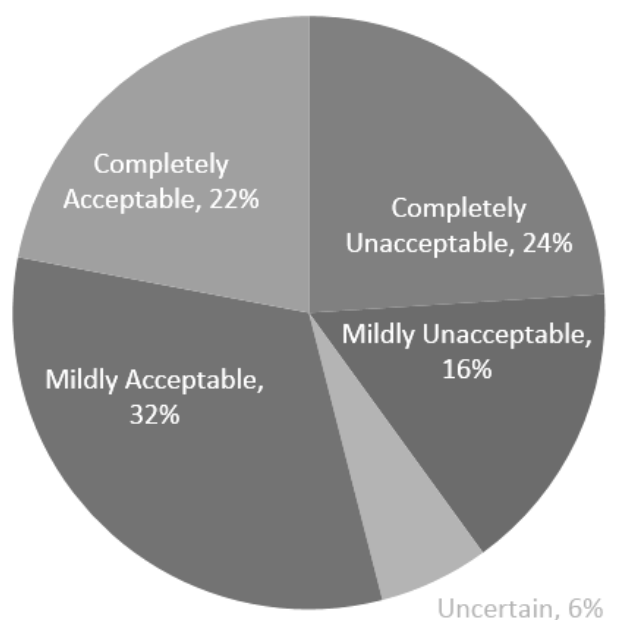

\author{
n Completely Unacceptable \\ - Mildly Unacceptable \\ - Uncertain \\ - Mildly Acceptable \\ - Completely Acceptable
}

Diagram 1. Responses to Statement 1 in Questionnaire 


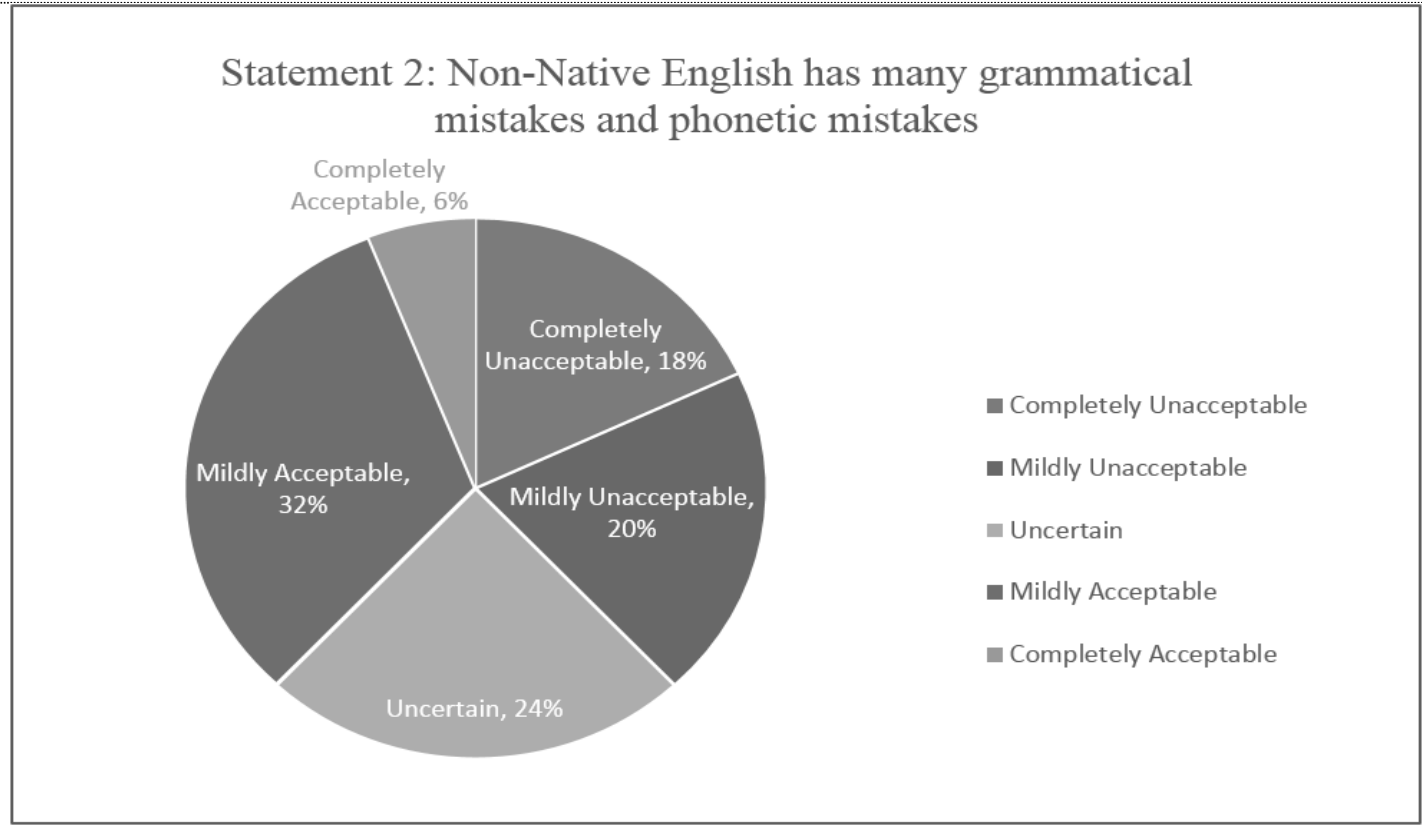

Diagram 2. Responses to Statement 2 in Questionnaire

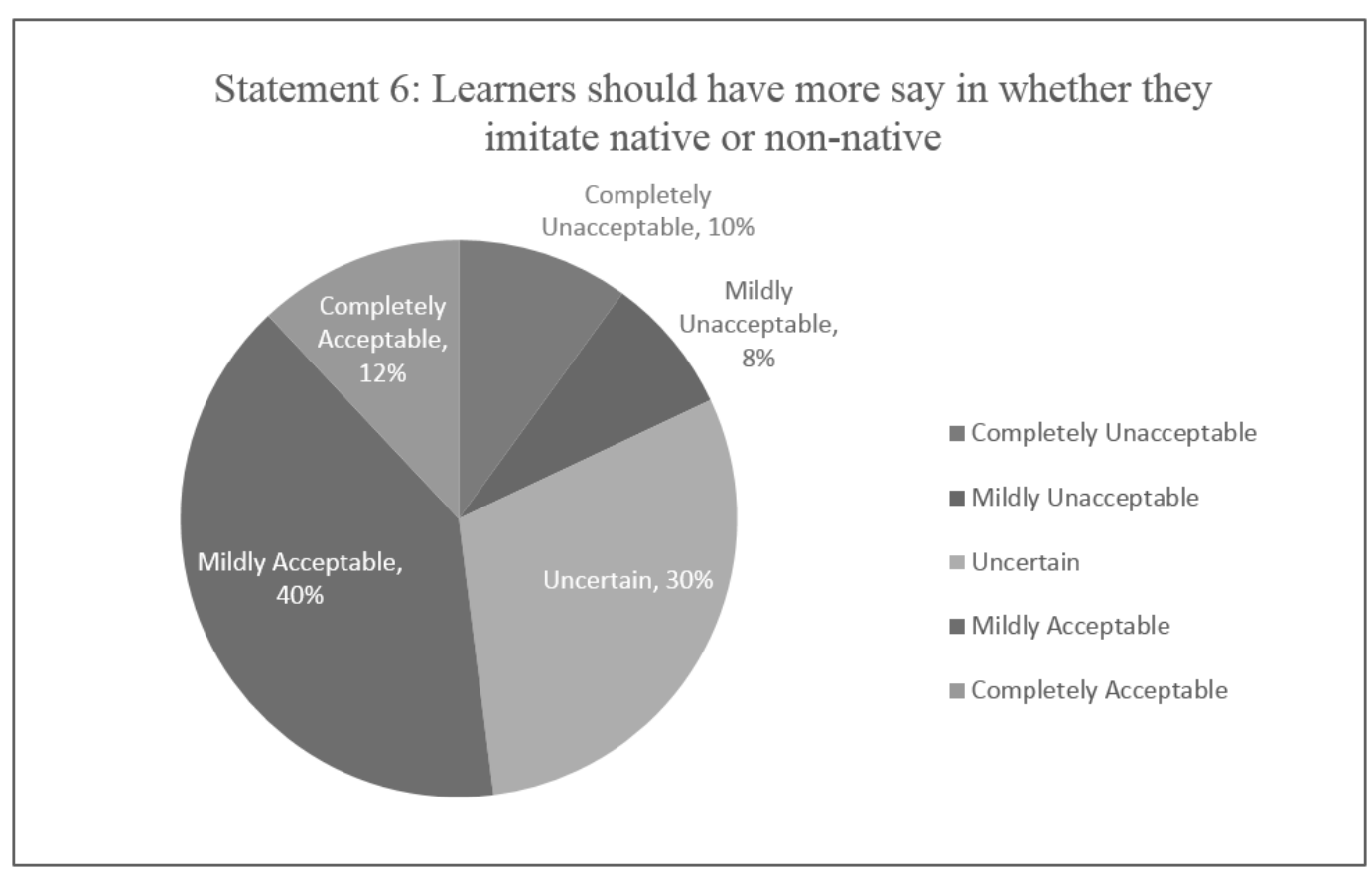

Diagram 3. Responses to Statement 6 in Questionnaire

\subsection{Teacher and Teaching}

Native English teachers and non-native English teachers are playing great roles in English teaching. As what have been discussed, native English teachers and non-native English teachers have many differences, which are manifested in their emphasis on different teaching contents and teaching methods. Students' attitudes towards the two groups can be viewed as their attitudes towards native English and non-native English to some degrees. From the survey, Chinese college students show their great respect to non-native English teachers. They also desire more possible English models appearing in course books in the future.

Statement 3 aims at finding out students' opinions on native English teacher and non-native English teacher. Almost a half (42\%) disagree that native English teachers are more authoritative than non-native English teachers. Compared with statement 9, more students can accept non-native English teachers' pronunciation. These manifest that Chinese college students accept non-native English teachers. What's more, they are open to different models of English. Statement 5 raises the issue of whether some more English varieties should be chosen for course books. The majority (70\%) agrees with it, which indicates that a large number of students do not regard native English as the only reference. They anticipate knowing different English forms. The move away from the current under-representation of lingua franca English use can be accepted by most students. 
Statement 3: Native English teacher are more authoritative than Non-Native English teacher

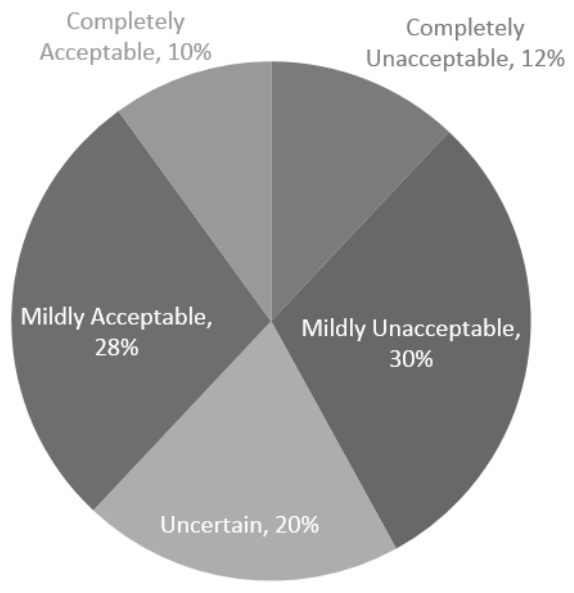

- Completely Unacceptable

- Mildly Unacceptable

Uncertain

- Mildly Acceptable

n Completely Acceptable

Diagram 4. Responses to Statement 3 in Questionnaire

Statement 5: Course books convey the notion that English is either British or American, but there are actually many different possible model for English in the world and I think there should be more nonnative varieties in course book

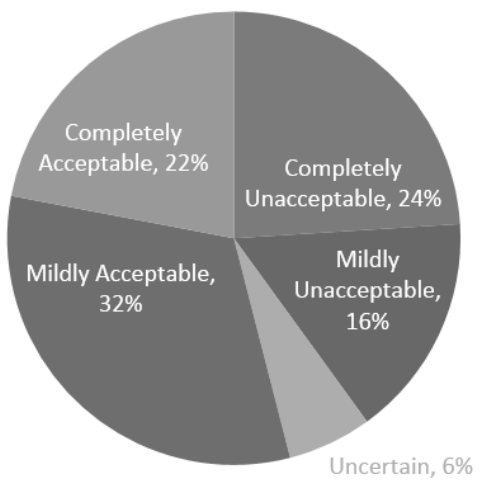

- Completely Unacceptable

Mildly Unacceptable

Uncertain

- Mildly Acceptable

- Completely Acceptable

Diagram 5. Responses to Statement 5 in Questionnaire

Statement 9: It is difficult for me to accept Non-Native English teachers' accent.

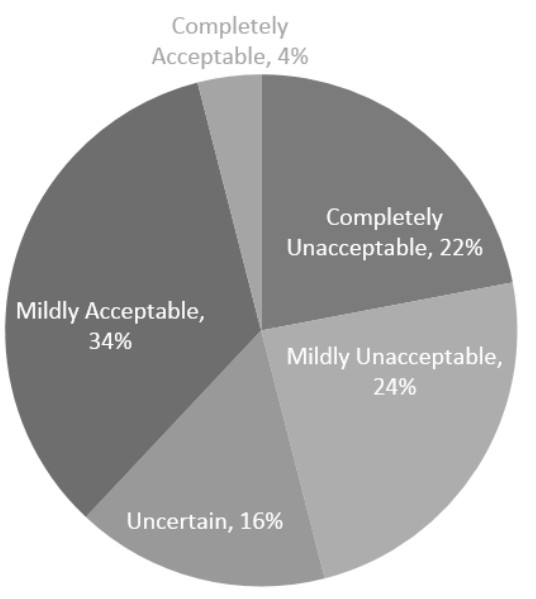

- Completely Unacceptable

Mildly Unacceptable

- Uncertain

- Mildly Acceptable

- Completely Acceptable

Diagram 6. Responses to Statement 9 in Questionnaire 


\subsection{Factors behind the Attitude}

Statement 7 takes up the issue of whether native English is better for students to find a job than non-native English. More than half $(56 \%)$ agree with it. From a different perspective, it reflects that society needs talents equipped with fluent and authentic English speaking skills. Native English is currently prestigious. Students are concerned with the perceived social advantage of native English. Statement 4 explores whether English teachers influence students' views on native English and non-native English. 52\% of students think that they know little about non-native English because seldom do their English teachers refer to it in class. It hints but not explicitly states that English teachers play an important for students on judging native English and non-native English. Teachers' attitudes towards native English and non-native English make a difference to students' views. Students' views on native English and non-native English depend on their self-expectation. 84\% of students hope their English as authentic as native speaker's. Statement 10 raises the discussion of the standard of English. More than half (52\%) of students agree that English is just a toll for communication. It is of no importance to be normal. They pay more attention to the function of language. While those who disagree with the statement $(42 \%)$ focus on the form of language. Different students have different needs. Some students may never need to, want to or be able to use English. For them, they just need to make themselves understood by foreigners, and they may never need to attain a native-like level. Under this circumstance, they choose the function of English. However, for those who have high expectations on themselves, they pay more attention to the form of English. That is, they are careful about the grammar, sentence structure, pronunciation and so on. In the open question, $60 \%$ of students who prefer non-native English think that it is good for them to keep their culture. They think language and culture are not separable, but are acquired together. Students who would like to know more about American or British culture are in favor of native English. Besides, both of the two camps believe that culture plays an instrumental role in shaping speakers' communicative competence, which is related to the appropriate use of language. As Zhu (2003) said, culturally unacceptable behaviors are worse than linguistic mistakes.

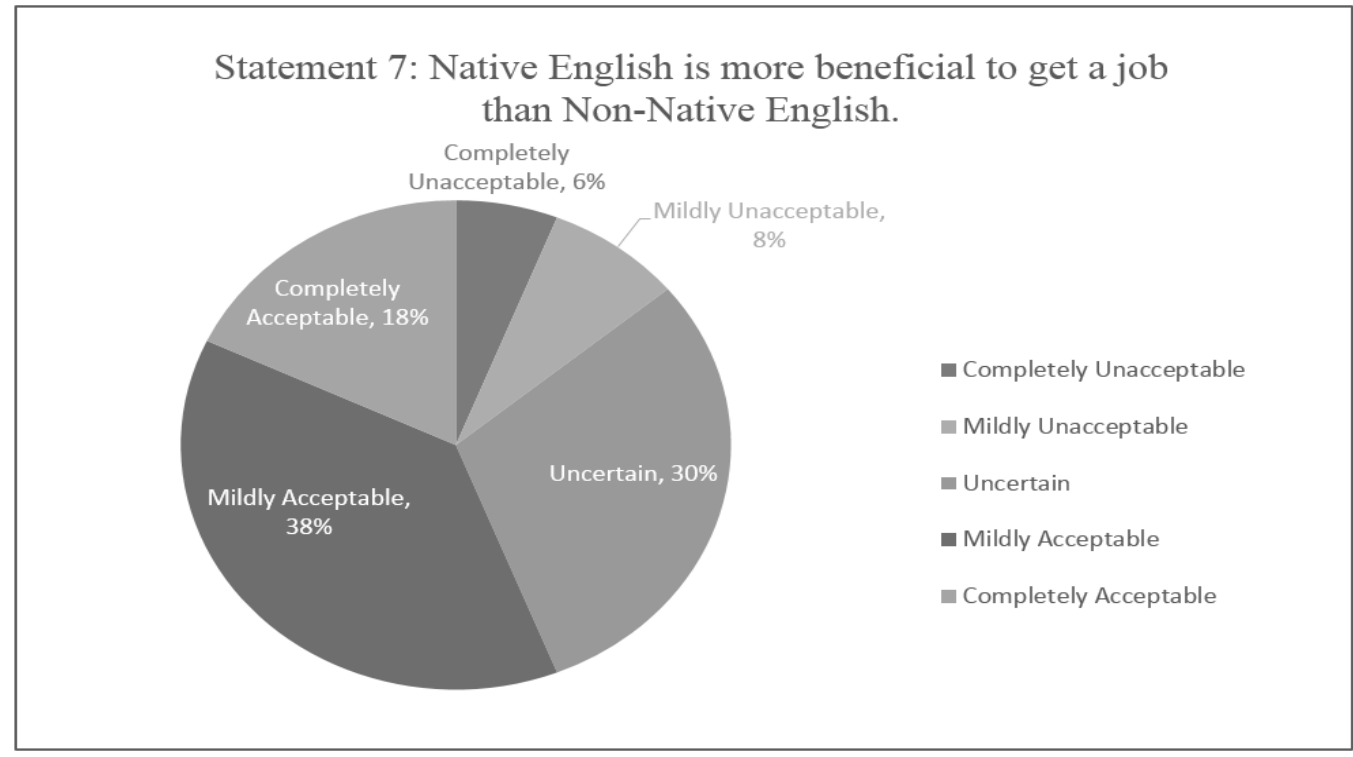

Diagram 7. Responses to Statement 7 in Questionnaire

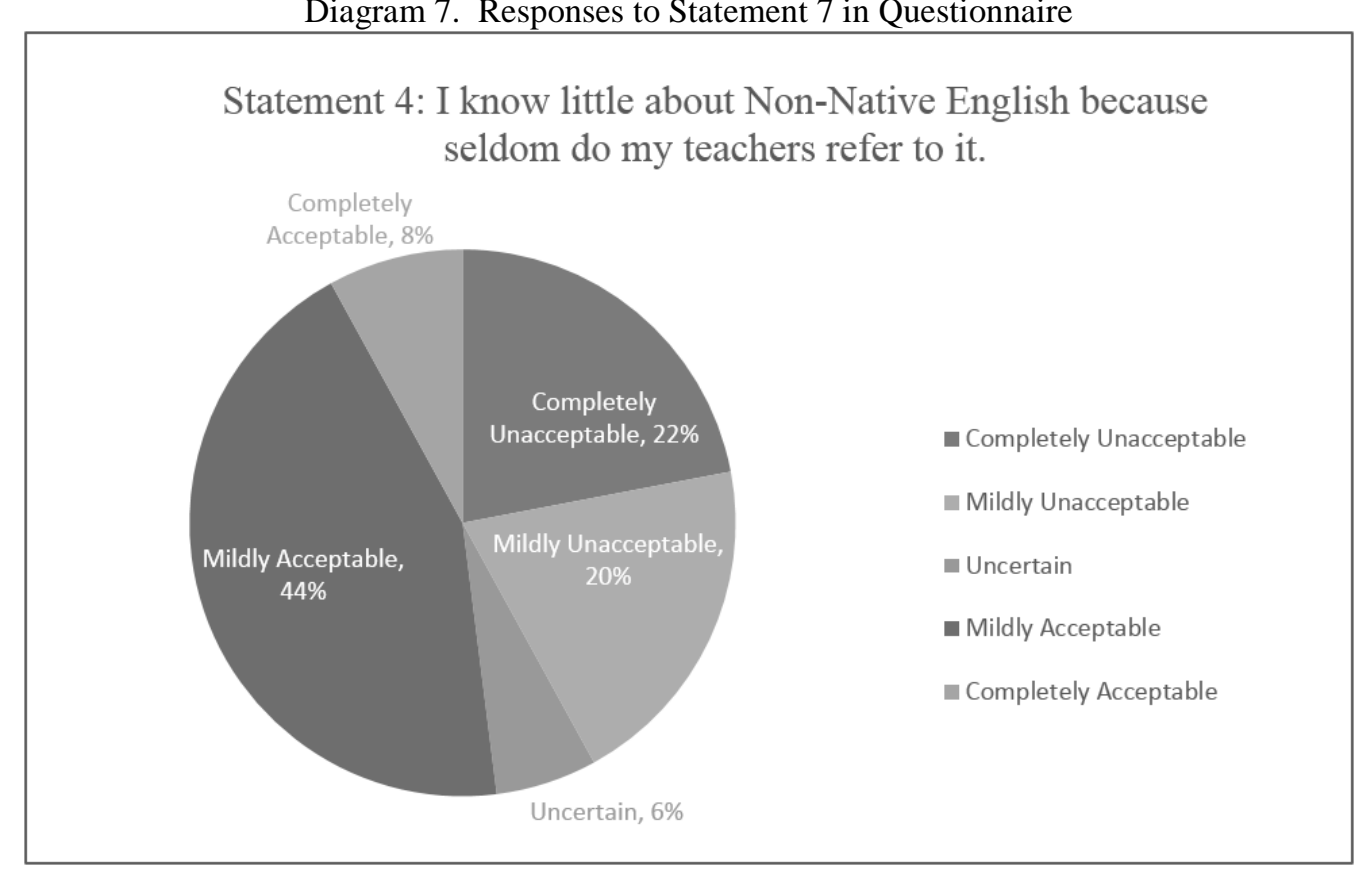

Diagram 8. Responses to Statement 4 in Questionnaire 


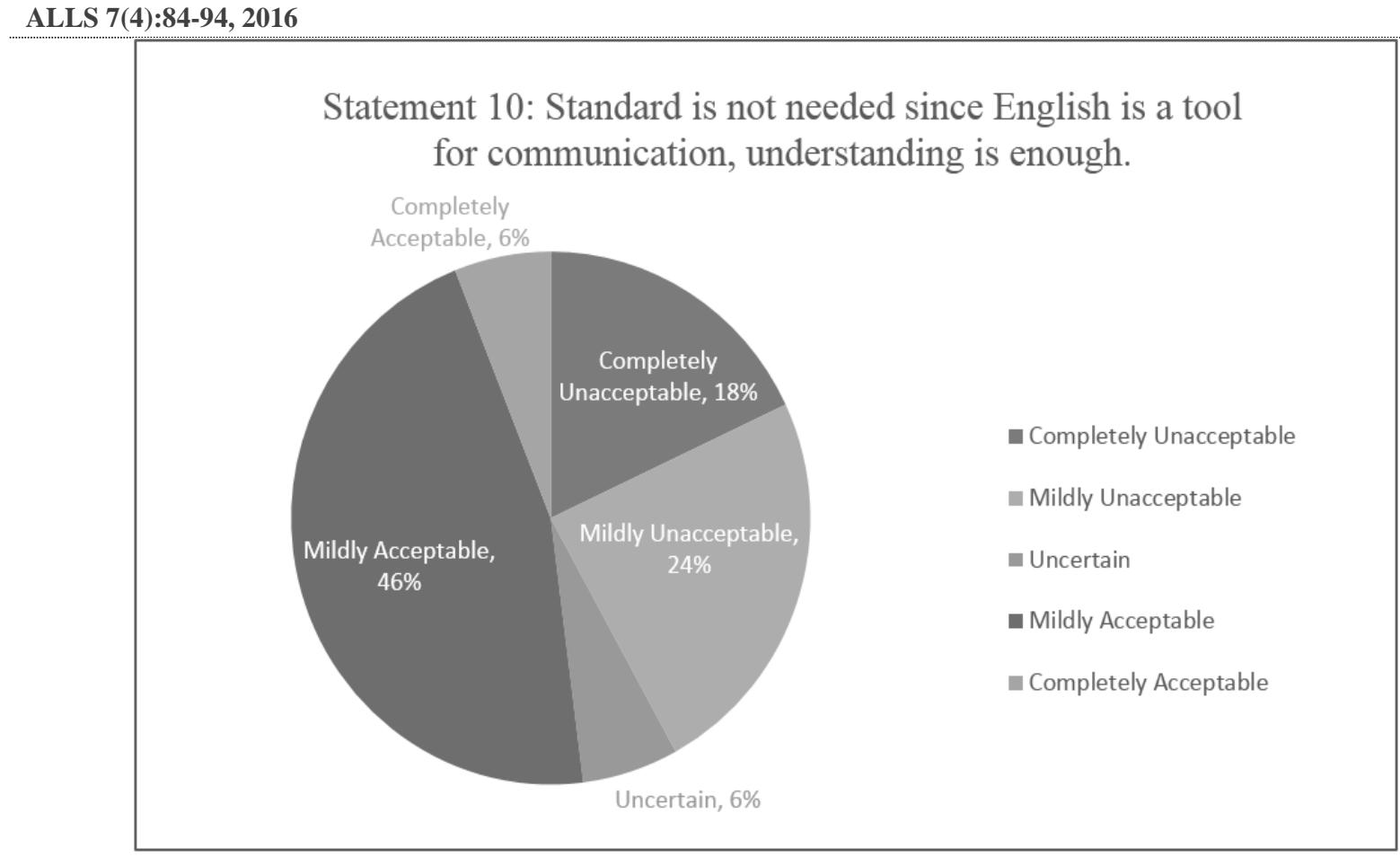

Diagram 9. Responses to Statement 10 in Questionnaire

\section{Discussion}

This study demonstrates Chinese college students' views on native English and non-native English. From a purely superficial level, they prefer native English than non-native English. However, the results of the study find that more and more students hold positive attitudes towards non-native English. It indicates that the preference for native English is only one side of Chinese college students' attitudinal picture. The tendency to non-native English should be highlighted. In Wang's (2013) study, she draws a similar conclusion that many Chinese students believe that real English equals ENL (English as a Native Language) and English that is not like ENL doesn't qualify the label of English. The preference can be explained by the inherent advantages and prestigious position of Native English. Chinese students have desire for fixed norms and aspiration for the perceived social advantage of ENL, which has already been proved by Wang (2013). As to the language itself, the describable phonetic, grammatical and lexical features are appreciated by Chinese students. When referred to language in use, native English possesses the function of enabling each nation to communicate with other countries and to collect new concepts and observe new movements to bring them back to analyzing the further necessary inputs. Companied with the globalization and the use of English, competition and corporation between different countries come up. Bull (2012) calls it border crossing, which implies inter-or transnational research collaboration, the use of lingua franca, student exchange and so on. With the world becomes closer, more importance are attached to English. In education, English becomes a compulsory course, and native English is seen as a 'real life' language (Timmis, 2002); in business, people armed with native English speaking skills are preferred; in scientific study, native English is becoming more prevalent not only as the lingua franca but also of instructions (Murray, 2013:116). Native English also has its prevalence in popular culture (Qu, 2007). All these factors consolidate the positive attitude towards native English. Some students focus on the form of language and believe in the authority of the mainstream English, while other students who choose non-native English hope to keep their own culture and protect their identity. It is similar to Wang's (2013) study, in which she thinks the World Englishes research has effectively defended outer circle user' right of using English in their way. Non-native speakers have their right to use English in their own way, by which they can display and spread their own culture as well as protect their own identity. There has been a large number of research concerned on the trend, such as two exceptions in Bull's (2012) study, Swiss English teachers attitudes to Euro-English in Murray's (2003) study and etc. In the study, a growing number of students show their respect to non-native English and expect to know English varieties in class. They also want to know more about different cultures of different countries rather than simple American culture or British culture. One of the most important functions of language is interpersonal. English as a language serves as a tool to communicate. Very few of students will ever need to attain a native-like level, although they may aspire to do so. Teachers testify to the fact that many non-English majors, and even some English majors, seem to want no more than a reading and working level of English at a practical spoken level (Ma, 2012:106). They pay more attention to the function of language. Timmis's (2002) study finally finds that there is no reason why it (Native English) should be, but it may be that some students want it to be. By the survey, students' wants and needs are exposed. However, it is impossible to adapt English language teaching totally to students' expectations. Too much emphasis on their requests is not reasonable. A better understanding of their attitudes together with deeper analysis of the reasons behind the attitude can provide some useful information in English teaching. 


\section{Conclusion}

It would be absurd to suggest that the survey provides a statistically accurate picture of the state of opinion among students: the sample is but a tiny fraction of the English language learning population, and the questionnaires are not precise instruments. I think, however, that the survey, given the number of responses and relatively wide geographical coverage, can support that from a purely superficial level, Chinese College students prefer native English than nonnative English. However, the results of the study show that a large number of students show their respect to non-native English and expect to know English varieties in class. It indicates that the preference for Native English is only one side of Chinese college students' attitudinal picture. The traditional idea of native English makes it prestigious for some students. However, there are also many students pointing out that non-native English also owns its shining points. They hope by using non-native English, they can protect their identity and culture. Their motivation to learn English is not just for academic purposes, but focuses more on practical aims. Considering the education policies and practices, this paper adds to voice the change of English language teaching.

\section{Acknowledgements}

The research is funded by Three Gorges University, China. No. 2015CX157 and Hubei Province Ministry of Education, China. No. 2013B071. We thank the support for this research.

\section{References}

Davi, S. R. (2011). Non-native English-speaking teachers (NNESTs) and professional legitimacy: a sociocultural theoretical perspective on identity transformation. English Teaching Forum, 35(4), 139-160.

Heather, M. (2003). Swiss English teachers and Euro-English: Attitude to a non-native variety. The English Teacher, 26(3), 147-165.

$\mathrm{Hu}$, X. (2004). The Development of Global English and Influences on China English Education under Globalization. Foreign Language Teaching, 25(7), 5-9.

Ivor, T. (2002). Native-speaker norms and International English: a classroom view. ELT Journal, 56(3), $240-249$.

Kingsley, B., and Graddol, D. (2012). English in China Today. English Today, 28(3), 3-9.

Lucie, M., and Enric, L. (2008). Non-native English-speaking English language teachers: History and research. Language Teaching, 41(3), 315-348.

Li, P. (2006). Chinese College Students' Expectation for Native English Teachers and Non-native English Teachers. Unpublished Master Thesis. Guangxi: Guangxi Normal University.

Ma, Q. (2012). Upholding Standards of Academic Writing of Chinese Students in China English. Changing English, 19(3), 349-357.

Peng, L. (2013). A Research on Chinese English Education Policy from Economics of Language Perspective. Unpublished Master Thesis. Yinchuan: Ningxia University.

Tove, B. (2012). Against the mainstream: universities with an alternative language policy. Linguistics and Education, $15(8), 55-73$.

Wang, Y. (2013). Non-conformity to ENL norms: a perspective from Chinese English users. JELF, 2(2), $255-282$.

Xie, X., and Jian, L. (2006). Challenges for Non-native English Teachers. Journal of Miaoming University, $21(8), 1317$.

Zhu, H. (2003). Globalization and New ELT Challenges in China. English Today, 19(4), 36-41.

\section{Appendix}

\section{Questionnaire}

\section{Chinese College Students Attitudes' on Native English and Non-native English}

Native English: American English and British English

Non-native English: Different usage of English from American English and British English, e.g. Australian English, Indian English, China English etc.

1 Native English sounds more beautiful and authentic than non-native English. A Completely Unacceptable B Mildly Unacceptable C Uncertain D Mildly Acceptable E Completely Unacceptable

2 Non-native English has many grammatical mistakes and phonetic mistakes. A Completely Unacceptable B Mildly Unacceptable C Uncertain D Mildly Acceptable E Completely Unacceptable 
4 I know little about non-native English because seldom do my teachers refer to it.

A Completely Unacceptable B Mildly Unacceptable C Uncertain D Mildly Acceptable E Completely Unacceptable

5 Course books convey the notion that English is either British or American, but there are actually many different possible models for English in the world and I think there should be more non-native varieties in course book. A Completely Unacceptable B Mildly Unacceptable C Uncertain D Mildly Acceptable E Completely Unacceptable

6 Learners should have more say in whether they imitate native English or non-native English. A Completely Unacceptable B Mildly Unacceptable C Uncertain D Mildly Acceptable E Completely Unacceptable

7 Native English is more beneficial to get a job than non-native English.

A Completely Unacceptable B Mildly Unacceptable C Uncertain D Mildly Acceptable E Completely Unacceptable

8 As an English major, I wish my English can be as good as native speakers.

A Completely Unacceptable B Mildly Unacceptable C Uncertain D Mildly Acceptable E Completely Unacceptable

9 It is difficult for me to accept non-native English teachers' accent.

A Completely Unacceptable B Mildly Unacceptable C Uncertain D Mildly Acceptable E Completely Unacceptable

10 Standard is not needed since English is a tool for communication, understanding is enough.

A Completely Unacceptable B Mildly Unacceptable C Uncertain D Mildly Acceptable E Completely Unacceptable

Open Question

Native English and non-native English, which one do you prefer? Why? 